\title{
Evaluation of the relationship between plaque formation leading to symptomatic carotid artery stenosis and cytomegalovirus by investigating the virus DNA
}

Metin Onur Beyaz ${ }^{1,2}$, Murat Ugurlucan ${ }^{1}$, Didem Melis Oztas ${ }^{1}$, Mert Meric $^{1}$, Cenk Conkbayir ${ }^{3}$, Ali Agacfidan ${ }^{4}$, Mustafa Onel ${ }^{4}$, Ufuk Alpagut ${ }^{1}$

\author{
'Department of Cardiovascular Surgery, Istanbul Medical Faculty, Istanbul University, \\ Istanbul, Turkey \\ 2Department of Cardiovascular Surgery, Umraniye Education and Research Hospital, \\ Istanbul, Turkey \\ ${ }^{3}$ Department of Cardiology, Near East University, Nicosia, Cyprus \\ ${ }^{4}$ Department of Microbiology, Istanbul Medical Faculty, Istanbul University, Istanbul, \\ Turkey
}

Submitted: 13 October 2018

Accepted: 2 February 2019

Arch Med Sci Atheroscler Dis 2019; 4: e19-e24

DOI: https://doi.org/10.5114/amsad.2019.83304

Copyright $\odot 2019$ Termedia \& Banach

\section{Abstract}

Introduction: The most common etiologic factor of coronary artery disease $(C A D)$, carotid artery disease, and peripheral artery disease is atherosclerosis. In our study, we aimed to show the effect of cytomegalovirus (CMV), which can occur almost everywhere in the human body, on triggering the chronic inflammatory process in the pathophysiology of atherosclerosis, and its presence and impact in the plaques leading to carotid artery stenosis.

Material and methods: Thirty-six patients, who underwent carotid endarterectomy at the Department of Cardiovascular Surgery, Istanbul University Istanbul Medical Faculty between April 2017 and April 2018, were included in this study upon their consent. Patients with additional immunosuppressive conditions were not included in the study. Unilateral atheromatous plaque was preferred for patients undergoing bilateral carotid endarterectomy and all risk factors (DM, $\mathrm{HT}$, hyperlipidemia, etc.) were evaluated together for all patients.

Results: When the relationship between CMV (DNA) presence in samples taken from patients' plaques and sex, age and comorbidities was examined, CMV (DNA) positivity (45.8\%) was significantly higher in DM patients than non-DM patients $(8.3 \%)(p=0.024)$. Likewise, CMV(DNA) positivity $(40 \%)$ was significantly higher in HT patients than in non-HT patients $(25 \%)(p=$ $0.008)$. CMV(DNA) positivity (63\%) was significantly higher in patients with bilateral carotid artery stenosis than patients without bilateral carotid artery stenosis $(0 \%)(p<0.001)$.

Conclusions: It has not yet been clarified whether CMV is a primary trigger for atherosclerosis on the vascular wall, or whether it presents incidentally due to its affinity. When CMV (DNA) positivity was examined according to the presence of bilateral carotid artery stenosis in our study, CMV (DNA) positivity was found to be significantly higher in patients with bilateral carotid artery stenosis (63.16\%).

Key words: plaque, cytomegalovirus, carotid artery stenosis.
Corresponding author:

Metin Onur Beyaz

Department

of Cardiovascular Surgery

Umraniye Education

and Research Hospital, Istanbul, Turkey

E-mail: metinonurbeyaz@ gmail.com 


\section{Introduction}

Atherosclerosis and its complications in the cardiovascular system are the most common cause of death and disability worldwide. The World Health Organization reported that $30 \%$ of all deaths were attributed to cardiovascular diseases in 2010, and it is estimated that by 2030 at least 23.3 million people will die because of cardiovascular disease every year [1].

Atherosclerosis causes many pathologies by affecting the vascular system in different parts of the body. The ischemia that occurs as a result triggers an inflammatory response in many organs [2]. The most common etiological cause of coronary artery disease (CAD), carotid artery disease and peripheral artery disease is atherosclerosis [3].

Stroke is one of the most important causes of death and disability in the world [4]. Approximately $87 \%$ of the strokes are ischemic, $10 \%$ due to intracerebral hemorrhage, and 3\% due to subarachnoid hemorrhage [5]. Seventy-five percent of ischemic strokes result from carotid artery stenosis [6].

The incidence of carotid artery disease increases with age and cardiovascular risk factors [7]. Significant carotid artery stenosis is closely related to the development of stroke and other cerebrovascular events. Other etiologic factors of carotid artery stenosis are fibromuscular dysplasia, kink formation due to elongation, traumatic occlusion, intimal dissection and chronic inflammatory angiopathy [8]. Medical treatment, endovascular intervention or surgical treatment is preferred in the treatment of carotid artery stenosis. In the current era, the gold standard treatment of atherosclerotic carotid artery stenosis is surgical therapy $[9,10]$.

Cytomegalovirus (CMV) is a member of the Herpesviridae family, which includes large, enveloped viruses containing double-stranded DNA. Like other forms of the herpes family, it has the ability to remain latent in the tissue following acute infection and reactivate when immunity is suppressed.

It is thought that CMV triggers the coagulation cascade, and induces atherosclerosis through the lipid metabolism modification following arterial wall injury and hypercholesterolemia.

In our study, we aimed to show the effect of CMV on triggering the chronic inflammatory process in the pathophysiology of atherosclerosis, and its presence and impact in the plaques leading to carotid artery stenosis.

\section{Material and methods}

We included 36 patients who underwent a carotid endarterectomy (CEA) operation at the Department of Cardiovascular Surgery, Istanbul University Istanbul Medical Faculty between April 2017 and April 2018 and regularly visited the outpatient clinic after the operation. The same surgeon (M.U.) operated on 35 patients and the remaining one was performed by a different surgeon.

Among 36 patients included in the study, $58.3 \%(n=21)$ were male and $41.7 \%(n=15)$ were female. $66.7 \%$ were 65 years old or over with a mean age of $67.5 \pm 9.6$ years and a median age of 68 years (minimum: 42, maximum: 85 ).

Patients with additional immunosuppressive conditions (malignancy, chronic autoimmune disease, AIDS, etc.) were not included in the study. Unilateral atheromatous plaque was preferred for patients undergoing bilateral carotid endarterectomy and all risk factors (DM, HT, hyperlipidemia, etc.) were evaluated together for all patients.

Age, sex, height and weight were initially recorded for each voluntary patient. Patients' body mass index (BMI) values were calculated. The diagnosis of hypertension, diabetes mellitus and chronic renal failure (CRF), presence of neurological symptoms before the operation, bilateral CEA operation necessity, history of smoking and alcohol use, previous cardiovascular interventions and family history were questioned. Preoperative carotid artery stenosis rates were provided from preoperative radiological imaging results (such as carotid duplex ultrasonography, computed tomography angiography, magnetic resonance angiography, and subtraction angiography).

All patients underwent conventional carotid endarterectomy. Operations were performed with continuous neurological evaluation during carotid arterial clamping under cervical regional block. A Dacron patch was used in all patients.

Samples taken from the patients after a conventional carotid endarterectomy procedure were placed into sterile petri dishes and pre-mechanically disintegrated with a scalpel. Subsequently, 400 $\mu \mathrm{l}$ of tissue lysis solution and $40 \mu \mathrm{l}$ of proteinase $\mathrm{K}$ were added to $2 \mathrm{ml}$ sterile Eppendorf tubes to perform $56^{\circ} \mathrm{C}$ overnight tissue disruption (Buffer ATL (Cat no: 939011), Proteinase K (Cat no: 19133; Qiagen)). Quantitation of CMV samples in the green channel was performed by PCR analysis. In the yellow channel, the internal control used during the isolation phase was assessed, which allows us to check the isolation and PCR stage correctly.

\section{Surgical technique}

Operations were performed under regional block and local anesthesia. The common carotid artery and the internal and external carotid arteries were prepared by an incision parallel to the sternocleidomastoid muscle. Following systemic heparinization (5000 IU), the arteries were clamped. The patient's consciousness and neurological status was evaluated prior to arteriotomy with oral stimulation and foot and hand move- 
ments on the contralateral half of the body in response to commands. Neurological deterioration was not detected in any patients. If neurological disorder was detected, endarterectomy would be performed with a shunt. Endarterectomy was performed after a standard longitudinal incision in all patients and internal carotid arteries were reconstructed using patch material. In patients with bilateral carotid artery stenosis, primarily, the symptomatic side was treated; otherwise the more stenotic side was operated on. The extracted plaque material was sent to the microbiology laboratory under appropriate conditions for microbiological examination.

\section{CMV-DNA analysis}

Clinical specimens obtained from the patients after conventional carotid endarterectomy were first subjected to physical disintegration with the help of a scalpel in sterile petri dishes. After the procedure, the shredded clinical specimens were placed in $20 \mathrm{mg}$ sterile Eppendorf tubes with 400 $\mu$ l of tissue lysis solution (Qiagen, Cat no: 939011), and $40 \mu \mathrm{l}$ of proteinase K (Qiagen, Cat no: 19133) was added, in accordance with the kit procedure, to perform overnight incubation at $56^{\circ} \mathrm{C}$. Then, $600 \mu \mathrm{l}$ of AVE solution was added into the Eppendorf tubes containing the clinical specimens, and CMV DNA extraction was performed. Extraction of the samples was performed using the DSP Virus/ Pathogen midi kit (Qiagen, Cat no. 937055) on the Qiasymphony SP/AS platform. PCR was performed using the Artur CMV QS-RGQ kit (24) (Cat no: 4503363) on a Rotorgene Q instrument. Assessment of the results was based on the Rotorgene $Q$ device in the green channel showing the presence of CMV DNA in clinical specimens and in the yellow channel displaying the internal control for any inhibition in the study.

\section{Statistical analysis}

All analyses were performed with the IBM SPSS Statistics software package (version 21.0, IBM, Ar-

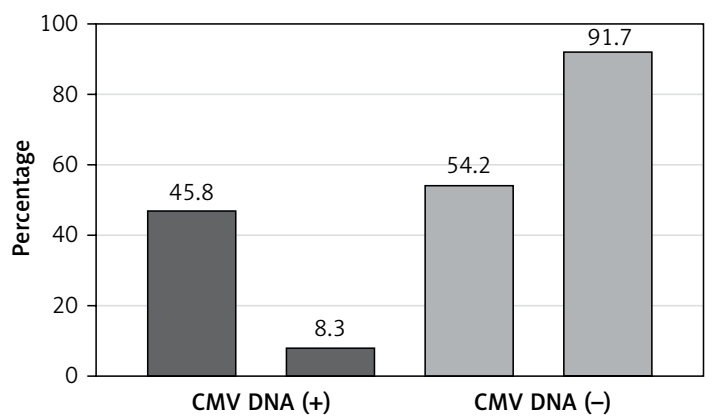

Figure 1. CMV (DNA) distribution according to the presence of DM
Table I. Demographic characteristics of patients

\begin{tabular}{|llc|}
\hline Parameter & $\boldsymbol{N}$ & $\%$ \\
\hline \begin{tabular}{l} 
Gender: \\
\hline Male
\end{tabular} & 21 & 58.3 \\
\hline Female & 15 & 41.7 \\
\hline Age [years]* & & \\
\hline$<65$ & 12 & 33.3 \\
\hline$\geq 65$ & 24 & 66.7 \\
\hline Diabetes mellitus & 24 & 66.7 \\
\hline Hypertension & 22 & 61.1 \\
\hline Hyperlipidemia & 20 & 55.6 \\
\hline Smoking & 32 & 88.8 \\
\hline${ }^{*}$ Mean age 67.5 \pm 9.6 and median age 68 (min.: 42 max.: 85).
\end{tabular}

monk, NY, USA) at the $95 \%$ confidence level and $p<0.05$ significance level. Quantitative variables were reported as the mean and standard deviation (SD); qualitative variables were described as numbers and percentages. Quantitative variables were analyzed by Friedman analysis for dependent groups. Subgroup analysis was performed by Wilcoxon analysis and interpreted by Bonferroni correction. The independent groups were compared with $\chi^{2}$ analysis.

\section{Results}

Thirty-six patients participated in the study. $58.3 \%(n=21)$ of the patients were male and $41.7 \%(n=15)$ were female. $66.7 \%$ of the patients were aged 65 years or over, with a mean age of $67.5 \pm 9.6$ years and a median age of 68 years (minimum: 42, maximum: 85 ). In terms of co-morbidity, $66.7 \%$ of the patients had DM, $61.1 \%$ had HT and $55.6 \%$ had hyperlipidemia. Twenty-four patients were active smokers and 8 patients were ex-smokers (Table I).

The relationships between the presence of CMV (DNA) and sex, age and comorbidities in the samples taken from the patients' plaques were examined: CMV (DNA) positivity (45.8\%) was sig-

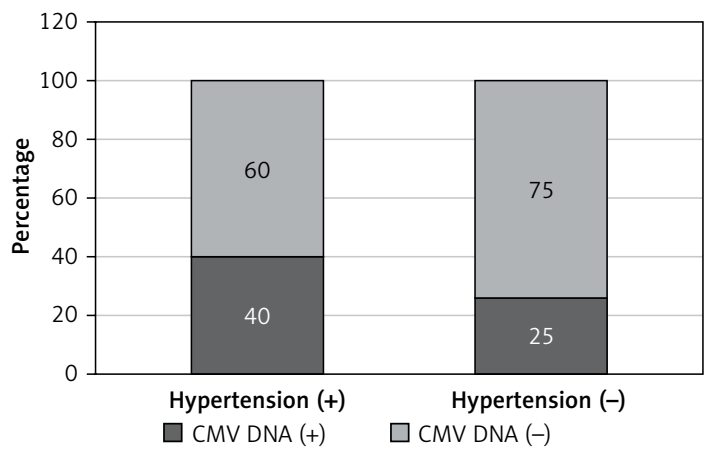

Figure 2. CMV (DNA) rates according to the presence of hypertension 
Table II. Relationship between CMV (DNA) positivity and gender, age and comorbidities

\begin{tabular}{|c|c|c|c|c|c|}
\hline \multirow[t]{3}{*}{ Parameter } & \multicolumn{4}{|c|}{ CMV (DNA) } & \multirow[t]{3}{*}{$P$-value } \\
\hline & \multicolumn{2}{|c|}{ Negative } & \multicolumn{2}{|c|}{ Positive } & \\
\hline & $N$ & $\%$ & $N$ & $\%$ & \\
\hline \multicolumn{6}{|l|}{ Gender: } \\
\hline Male & 14 & 66.7 & 7 & 33.3 & 1.00 \\
\hline Female & 10 & 66.7 & 5 & 33.3 & \\
\hline \multicolumn{6}{|l|}{ Age [years]: } \\
\hline$<65$ & 9 & 75.0 & 3 & 25.0 & 0.453 \\
\hline$\geq 65$ & 15 & 62.5 & 9 & 37.5 & \\
\hline \multicolumn{6}{|c|}{ Diabetes mellitus: } \\
\hline Negative & 11 & 91.7 & 1 & 8.3 & 0.024 \\
\hline Positive & 13 & 54.2 & 11 & 45.8 & \\
\hline \multicolumn{6}{|c|}{ Hypertension: } \\
\hline Negative & 12 & 75.0 & 4 & 25.0 & 0.008 \\
\hline Positive & 12 & 60.0 & 8 & 40.0 & \\
\hline \multicolumn{6}{|c|}{ Hyperlipidemia: } \\
\hline Negative & 13 & 92.9 & 1 & 7.1 & 0.343 \\
\hline Positive & 11 & 50.0 & 11 & 50.0 & \\
\hline \multicolumn{6}{|c|}{ Bilateral carotid artery stenosis: } \\
\hline Negative & 17 & 100.0 & 0 & 0 & $<0.001$ \\
\hline Positive & 7 & 36.8 & 12 & 63.2 & \\
\hline Total & 24 & 66.7 & 12 & 33.3 & \\
\hline
\end{tabular}

Table III. CMV (DNA) positivity rates based on the presence of bilateral carotid artery stenosis

\begin{tabular}{|c|c|c|c|c|c|}
\hline \multirow{3}{*}{$\begin{array}{l}\text { Bilateral carotid } \\
\text { artery stenosis }\end{array}$} & \multicolumn{4}{|c|}{ CMV DNA } & \multirow[t]{3}{*}{$P$-value } \\
\hline & \multicolumn{2}{|c|}{ Negative } & \multicolumn{2}{|c|}{ Positive } & \\
\hline & $N$ & $\%$ & $N$ & $\%$ & \\
\hline Negative & 17 & 100.00 & 0 & 0.00 & $<0.001$ \\
\hline Positive & 7 & 36.84 & 12 & 63.16 & \\
\hline
\end{tabular}

nificantly higher in DM patients than in non-DM patients $(8.3 \%)(p=0.024)$. Similarly, CMV (DNA) positivity (40\%) was significantly higher in $\mathrm{HT}$ patients than in non-HT patients $(25 \%)(p=0.008)$.

When CMV (DNA) positivity was examined according to the presence of bilateral carotid artery stenosis, the rate of CMV (DNA) positivity was found to be significantly higher in patients with bilateral carotid artery stenosis (63.16\%) compared to patients without bilateral carotid artery stenosis $(p<0.001)$ (Table II, III, Figures 1-3).

When plaque quantities were compared according to the gender, CMV (DNA), bilateral carotid artery stenosis and co-morbidity, the median value of sample quantities in patients with bilateral carotid artery stenosis (1280.00) was significantly higher than that in the patients without bilateral carotid artery stenosis. Similarly, the median value (1340.00) of sample quantities from patients with CMV (DNA) was significantly higher than that of the CMV (DNA) negative patients (Table IV).

\section{Discussion}

The potential pathological mechanism of atherosclerosis is still unclear, and it is known that certain risk factors such as hypertension, hyper- 
cholesterolemia, smoking, hyperlipidemia, diabetes, and genetic predispositions are important factors. In addition, the number of studies suggesting that infectious agents such as $C$. pneumoniae, $H$. pylori and some herpesviruses may be effective in the development of atherosclerotic pathology by triggering an inflammatory response in vascular tissues has increased in recent years [11-13].

Human CMV (HCMV), one of the most studied viruses associated with atherosclerosis, is an important human pathogen that causes disease especially in immunosuppressed hosts and remains persistently in the host after primary infection as a highly complex virus. There are many studies suggesting that CMV may cause a latent infection in the vascular wall, resulting in an inflammatory process with reactive damage, leading to the onset of atherosclerosis. However, there are studies that find contradictory results with this opinion. It is not clear yet whether this virus triggers atherosclerosis primarily, or secondarily through a pre-existing lesion due to its affinity $[12,13]$.

In the literature, there are a limited number of publications about the relationship between CMV seropositivity and gender. According to the study

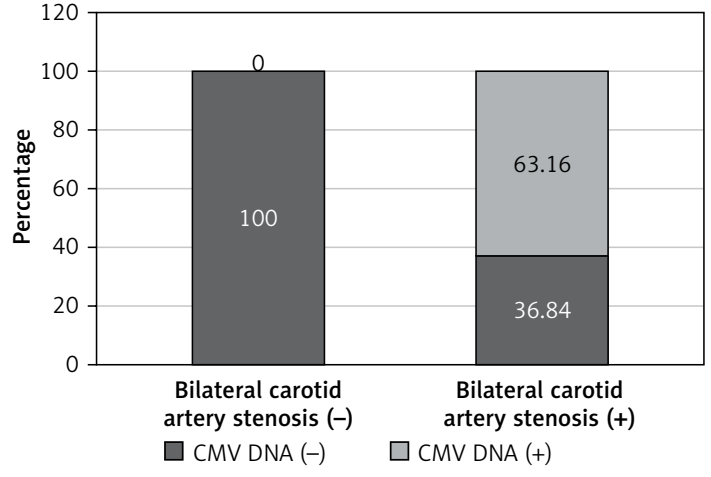

Figure 3. Graph showing the rates of CMV (DNA) positivity according to the presence of bilateral carotid artery stenosis

performed by Mayr et al. [14] in 2000, CMV seropositivity was found significantly higher in women than men $(p<0.001)$ in patients with carotid and femoral artery atherosclerosis. In contrarst, Zhu et al. [15] reported that CMV seropositivity was significantly higher in males than females in patients with atherosclerosis based on coronary artery disease $(p<0.001)$. According to this, the distribution of CMV seropositivity by gender varies in a small number of studies.

Table IV. Amount of samples taken from patients compared to gender, CMV (DNA), bilateral carotid artery stenosis and presence of comorbidity

\begin{tabular}{|c|c|c|c|c|}
\hline \multirow[t]{2}{*}{ Parameter } & \multicolumn{3}{|c|}{ Amount of samples [mg] } & \multirow[t]{2}{*}{$P$-value } \\
\hline & Median & Mean & SD & \\
\hline \multicolumn{5}{|l|}{ Gender: } \\
\hline Male & 1000.00 & 1075.24 & 483.71 & \multirow[t]{2}{*}{0.248} \\
\hline Female & 670.00 & 930.67 & 576.04 & \\
\hline \multicolumn{5}{|c|}{ Diabetes mellitus: } \\
\hline Negative & 665.00 & 838.33 & 448.61 & \multirow[t]{2}{*}{0.131} \\
\hline Positive & 1000.00 & 1103.33 & 541.03 & \\
\hline \multicolumn{5}{|c|}{ Hypertension: } \\
\hline Negative & 685.00 & 817.86 & 394.25 & \multirow[t]{2}{*}{0.119} \\
\hline Positive & 1195.00 & 1140.45 & 560.48 & \\
\hline \multicolumn{5}{|c|}{ Hyperlipidemia: } \\
\hline Negative & 895.00 & 1030.00 & 563.56 & \multirow[t]{2}{*}{0.949} \\
\hline Positive & 890.00 & 1003.00 & 499.34 & \\
\hline \multicolumn{5}{|c|}{ Bilateral carotid artery stenosis: } \\
\hline Negative & 630.00 & 757.65 & 398.24 & \multirow[t]{2}{*}{0.005} \\
\hline Positive & 1280.00 & 1245.26 & 518.39 & \\
\hline \multicolumn{5}{|l|}{ CMV (DNA): } \\
\hline Negative & 675.00 & 865.83 & 469.77 & \multirow[t]{2}{*}{0.024} \\
\hline Positive & 1340.00 & 1313.33 & 507.23 & \\
\hline
\end{tabular}


In our study, 33.3\% CMV (DNA) positivity was detected in the atherosclerotic tissue specimens belonging to the patient group. In the literature, there are some studies that showed different results from ours. Watt et al. [12] studied 16 atherosclerotic carotid artery tissues, and Müller et al. [16] studied 53 carotid artery plaques, and they did not detect CMV (DNA) in any tissue sample. Likewise, in 2005, Ibrahim et al. [17] found 10\% CMV (DNA) positivity in atherosclerotic tissue samples taken from 46 coronary and 2 carotid arteries, without detecting CMV (DNA) in non-atherosclerotic tissue specimens, but they reported that there was no statistical correlation among the findings. In our country, in 2006, Kılıç et al. [18] found CMV (DNA) positivity in $37.9 \%$ of the atherosclerotic tissue specimens taken from coronary, carotid and abdominal arteries and $32.7 \%$ of the non-atherosclerotic tissue specimens and also reported that there was no significant difference between them.

Our study is based on a single center and a limited number of patients' experiences. Although we found high CMV (DNA) positivity in specimens, we could not identify whether CMV triggers the pathway that leads to atherosclerosis. These may be considered as limitations of our study.

Although CMV (DNA) has not been identified in some international studies, we believe that the presence of CMV (DNA) positivity in 12 (33.3\%) cases in our study and the high rates of the presence of CMV (DNA) in atherosclerotic tissue samples in many international studies may reinforce the claims that it may play a role in the etiopathogenesis of atherosclerosis as a primary agent, rather than being secondary due to its affinity to the tissue.

In conclusion, our results show a significant relationship between CMV and atherosclerosis, but further studies are needed. Especially, when CMV (DNA) positivity is examined according to the presence of bilateral carotid artery stenosis in our study, CMV (DNA) positivity was found significantly higher in patients with bilateral carotid artery stenosis than in those without (63.16\%). High positive rates suggest that $\mathrm{CMV}$, an important component of the chronic inflammatory process, is a pathogen that should be considered seriously on the basis of atherosclerosis.

\section{Acknowledgments}

The manuscript contains data related to the thesis of Metin Onur Beyaz, MD. Metin Onur Beyaz is grateful to Onur Selcuk Goksel for his help on the thesis.

\section{Conflict of interest}

The author declare no conflict of interest.

\section{References}

1. Badimon L, Vilahur G. Thrombosis formation on atherosclerotic lesions and plaque rupture. J Intern Med 2014; 276: 618-32.

2. Umaroglu Ozturk S, Tireli E, Yılmazbayhan D, Ergen A, Ugurlucan M. The effect of L-carnitine on cardiac injury in an experimental aortic ischemia-reperfusion injury model. Damar Cer Derg 2018; 27: 142-9.

3. Enar R. Ateroskleroz - Aterotromboz. I.U. Cerrahpasa Tıp Fakultesi Surekli Tıp Egitimi Etkinlikleri Ateroskleroz; Koroner, Serebral, Periferik Arter Tutulumu Sempozyum Dizisi 2006; 52: 9-27.

4. Rutherford's Vascular Surgery. $8^{\text {th }}$ edn. Elsevier Saunders, Philadelphia 2014; 1456-95.

5. Roger VL, Go AS, Lloyd-Jones DM, et al. Heart disease and stroke statistics - 2012 update: a report from the American Heart Association. Circulation 2012; 125: e2-220.

6. Rockman CB, Jacobowitz GR, Gagne PJ, et al. Focused screening for occult carotid artery disease: patients with known heart disease are at high risk. J Vasc Surg 2004; 39: 44-51.

7. Erdinc I, Oztas DM, Demir I, Ugurlucan M, Tankut Akay H. Medical treatment experience following carotid endarterectomy in atrial fibrillation presenting with carotid artery stenosis. Damar Cer Derg 2018; 27: 085-090.

8. Kan P, Mokin M, Dumont TM, Snyder KV, Siddiqui AH. Cervical carotid artery stenosis: latest update on diagnosis and management. Curr Probl Cardiol 2012; 37: 127-69.

9. Oztas DM, Ugurlucan M, Onal Y, Sencer S, Alpagut U. Surgical treatment of localized internal carotid artery dissection: a case report. Damar Cer Derg 2018; 27: 154-8.

10. Erdinc I, Melis Oztas D, Ugurlucan M, Eray Yıldız C. Simultaneous treatment of carotid artery stenosis and kinking with regional cervical block. Damar Cer Derg 0; o(0).

11. Castelli W. Epidemiology of coroner artery disease. Am J Med 1984; 76: 4-12.

12. Watt S, Aesch B, Lanotte P, Tranquart F, Quentin R. Viral and bacterial DNA in carotid atherosclerotic lesions. Eur J Clin Microbiol Infect Dis 2003; 22: 99-105.

13. Melnick JL, Adam E, Debakey M. Possible role of cytomegalovirus in atherogenesis. JAMA 1990; 263: 2204-7.

14. Mayr M, Kiechl S, Willeit J, Wick G, Xu Q. Infections, immunity, and atherosclerosis: associations of antibodies to Chlamydia pneumoniae, Helicobacter pylori, and Cytomegalovirus with immune reactions to heat-shock protein 60 and carotid or femoral atherosclerosis. Circulation 2000; 102: 833-9.

15. Zhu J, Quyyumi AA, Norman JE, Csako G, Epstein SE. Cytomegalovirus in the pathogenesis of atherosclerosis: the role of inflammation as reflected by elevated C-reactive protein levels. J Am Coll Cardiol 1999; 34: 1738-43.

16. Müller BT, Huber R, Henrich B, et al. Chlamydia pneumoniae, herpes simplex virus and cytomegalovirus in symptomatic and asymptomatic high-grade internal carotid artery stenosis. Does infection influence plaque stability? Vasa 2005; 34: 163-9.

17. Ibrahim Al, Obeid MT, Jouma MJ, et al. Detection of herpes simplex virus, cytomegalovirus and Epstein-Barr virus DNA in atherosclerotic plaques and in unaffected bypass grafts. J Clin Virol 2005; 32: 29-32.

18. Kilic A, Onguru O, Tugcu H, Kilic S, Guney C, Bilge Y. Detection of cytomegalovirus and Helicobacter pylori DNA in arterial walls with grada III atherosclerosis by PCR. Pol J Microbiol 2006; 55: 333-7. 